\title{
A brutalização da escrita: perecimento e precariedade em Uma duas, de Eliane Brum
}

Tatiana Pequeno (UFF)

Recebido 13 ago. 2013/Aprovado 23 abr. 2014

\section{Resumo}

O primeiro romance de Eliane Brum Uma duas suscita inúmeras reflexões a respeito das tradições e discursos (pós)humanistas. Construída a partir do conflito de subjetividades (de uma filha e de sua mãe), a narrativa busca compreender em que medida um legado doentio de relações humanas confronta os individuos com seus permanentes estados de precariedade e ruina por meio de uma memória agressiva. A primeira parte do artigo procura ler a narrativa a partir de suas conexões com os sentidos pós-humanistas dela derivados, buscando compreender a brutalização como perda da aura tanto do individuo quanto de suas obras. A segunda parte do texto pretende discutir em que medida a escrita realoca a personagem Laura na sua humanidade, libertando-a da razão distópica de sua identidade híbrida porque geminada ao "seio grande e duro" de Maria Lúcia, sua mãe.

Palavras-chave: literatura brasileira contemporânea; Eliane Brum; poética da ruína. 
Em que medida a escrita de um romance pode sanar um conjunto de subjetividades arruinadas pelo excesso de real enquanto sofrimento? Como a obra opera as transformações de sua época, tornando-se não mais objeto salvífico, mas lugar de uma encarnação maléfica cuja execução é necessária para que o narrador sobreviva ainda que sob a inscrição da impossibilidade e da nulidade: "O fracasso previamente assumido ao tentar transformar vida em palavra. (...) Um romance é sempre um filho. Mas é um filho do inferno. E é legião." (BRUM, 2011, p. 176)

As questões que impulsionam o romance da jornalista Eliane Brum não correspondem apenas ao parágrafo introdutório de nossa leitura. Famosa pelas intervenções críticas sobre o mundo contemporâneo que vão além da articulação descritiva do universo jornalístico atual, onde suas crônicas dialogam corajosamente com as urgências do Contemporâneo, seja ele uma permanente e vertical análise da questão indígena, seja ele a tarefa da discussão sobre o lugar da escola ou sobre o aborto. Para sintetizar, é perfeitamente claro que Eliane Brum não se furta das discussões mais acaloradas e polêmicas de nossa época. Está, pelo contrário, atenta aos sentidos e sentimentos arruinados de nosso tempo, procurando investir quase sempre numa escrita que não abdica de abordar os núcleos de nossas subjetividades atravessadas pela precariedade, pela hipocrisia e pela miserabilidade.

\section{As provocações dilemáticas}

Articular historicamente o passado não significa conhecê-lo "como ele de fato foi". Significa apropriar-se de uma reminiscência, tal como ela relampeja no momento de um perigo.

Walter Benjamin, Sobre o conceito de História

Uma duas, romance de estreia de Brum, não é facilmente resumível. Introdutoriamente poderíamos afirmar tratar-se de um enredo cujo conflito é a relação entre a filha Laura e sua mãe Maria Lúcia como o cinema e o mundo editorial bem conhecem por meio de clássicos como Sonata de Outono (Ingmar Bergman, 1978) ou o clássico best-seller de Christina Crawford, Mamãezinha querida (1980). Em ambas as referências, encenações diferentes do rigor das relações familiares e da potência da crueldade nos espaços em que o poder também se agrega à intimidade.

Se o cinema e a literatura são capazes de aferir a partir do princípio da verossimilhança ou do princípio de plausibilidade a 
categoria de "obra", como lidamos com a imbricação entre o real e a ficção na produção pós-humanista? A narração de Uma duas entende o seu lugar de conflito e, na primeira página, anuncia:

Começo a escrever este livro enquanto minha mãe tenta arrombar a porta com suas unhas de velha. Porque é realidade demais para a realidade. Eu preciso de uma chance. Eu quero uma chance. Ela também.

Quando digito a primeira palavra o sangue ainda mancha os dentes da boca do meu braço. Das bocas todas do meu braço. Depois da primeira palavra não me corto mais. Eu agora sou ficção. Como ficção posso existir. (BRUM, 2011, p. 8, grifos nossos)

O que nos interessa, aqui, é exatamente a autorização da condição de existência, isto é, uma busca pela compreensão do que não permitiria que tal matéria de escrita fosse real. Ou seja, se é só por meio da ficção que o livro e sua matéria são autorizados, o que há nesta narração que impede esta primeira narradora de existir enquanto não-ficção? Cremos que, para tanto, seja fundamental proceder às exigências da leitura. Eduvidar, sobretudo, do texto nas suas entabulações de gênero. Isto porque a própria narratividade do livro se apresenta de maneira polifônica, por meio de pelo menos três perspectivas diferentes: primeira pessoa, na voz de Laura; terceira pessoa onisciente; e uma outra primeira pessoa na voz da mãe, Maria Lúcia. Este reconhecimento é facilitado pela mudança não só da fonte das letras em cada capítulo como também pelo processo de caracterização destas fontes: a voz da mãe está sempre marcada pelo uso do itálico, da $3^{\mathrm{a}}$. pessoa onisciente em negrito, enquanto a voz de Laura é grafada sem qualquer caracterização desta ordem - no modo "normal" das fontes, como se verifica nos programas utilizados para edições de texto.

O romance de Eliane Brum, impelido pelos narradores a ser objeto de descarga e maternidade do abjeto (uma legião composta por filhos do inferno, lembremos), apresenta como fundamento de seu enredo uma série de conflitos que vão de encontro a um postulado literário-humanista que valorizava os sentidos harmônicos e lineares de então. Nesse sentido, é possível evocar o que sugere Peter Sloterdijk (2000), em Regras para o parque humano - uma resposta à carta de Heidegger sobre o Humanismo: "O tema latente do humanismo é, portanto, o desembrutecimento do ser humano, e sua tese latente é: as boas leituras conduzem à domesticação. (p.17)". Com efeito, Uma duas vai de encontro à proposta humanista sentenciada pelo filósofo alemão na medida em que se constitui como discurso de uma história brutal em que a falência, a queda e o terror já são introduzidos no segundo capítulo:

A porta aberta. Demora a compreender a porta aberta. Onde a mãe está? Ela não enxerga. Um toque quase imperceptível na canela direita. A mãe. A carne enrodilhada no chão é a mãe. Quando o reconhecimento alcança seu cérebro como 
uma daquelas balas que se espatifam por dentro em milhões de estilhaços, ela grita. E por um instante está no fundo da piscina berrando no silêncio enquanto a água lhe enche os pulmões e a leva para um lugar sem sofrimento. (...) Desta vez, porém, é sua a voz que grita diante da carne enrodilhada aos seus pés. Finalmente o grito preso ali se solta. E ela sente que nunca mais o grito cessará, que aquele grito é para sempre, é um grito para toda a vida e para além da vida. Porque agora ela alcança a inteireza do horror. E gritos são coisas que não viram palavras, palavras que não podem ser ditas. Não há como escapar da carne da mãe. O útero é para sempre. (BRUM, 2011, p. 15, grifos nossos)

O desembrutecimento ao qual alude Peter Sloterdijk é impossível na história de Laura e Maria Lúcia exatamente porque nesta narrativa a violência das relações e dos diálogos constitui a quebra da unidade e da aura dos sujeitos do Humanismo, inimagináveis para a experiência fracionada que o título de Eliane Brum já adianta. Uma duas coincide, portanto, com a impossibilidade de integridade de suas protagonistas. Sempre à beira do choque e do esfacelamento que a subjetividade arruinada provoca, ambas as personagens rivalizam de diversos modos a paridade previsível para suas identidades familiares. Tal como Walter Benjamin entende os estilhaços das ruínas como centelhas do que foi uma experiência de fulgor e intensidade para o humano na Origem do drama barroco alemão, o romance de Brum também alegoriza a queda e o perecimento desejosos de promessa e salvação.

Um modo complementar de discutir a problemática pós-humanista do romance de estreia de Brum é procurando observar como o duplo, a fração e a impossibilidade da inteireza servem para ilustrar o humano diante da sua própria perda. São sucessivos os episódios em que tanto Laura quanto Maria Lúcia enfrentam situações em que a unidade ou a duplicidade de suas subjetividades são colocadas em xeque. Quando a filha retorna ao apartamento deixado pela mãe semimorta no chão ("a carne enrodilhada"), tem por intenção vingar-se do gato que, desesperado e sem alimentação por semanas, acabou também ele enfrentando a própria animalidade ao comer parte do pé de Maria Lúcia:

Entra no apartamento se esgueirando, à procura de um pedaço de pau ou de ferro, algo para bater no gato até torna-lo mais uma mancha orgânica no chão. Com outro rugido, o gato salta sobre seu rosto a sufocando, as unhas das patas fincadas em ambos os lados da parte posterior da sua cabeça (...). Ela sente o monstro dentro dela respondendo ao monstro de fora. E gosta. (BRUM, 2011, p. 24)

O duelo entre Laura e o gato aparece como ilustração do confronto humano com sua própria animalidade, questão fundamentalmente cultural e política como afirmou Giorgio Agamben não apenas no mais recente The Open: Man and Animal como no mais antigo A Linguagem e a morte. Tendo, como Sloterdijk, 
fundamento a partir da obra de Heidegger, Agamben realoca a animalização como problema (e consequência) do quadro (social e portanto político) moderno, uma vez que a ele corresponde cada vez mais o conceito de vida nua. É lógico que, nesse sentido, o problema da vida nua no romance de Eliane Brum deva ser formulado a partir da personagem Maria Lúcia, a mãe idosa colocada à mercê das vontades e dos fetiches sádicos de médicos e da própria filha.

Com efeito, a operacionalização do texto a partir de diversos princípios de duplicidade e oposição pode ser entendida como estratégia narrativa que visa à discussão não sobre a amizade ou sobre os enlaces humanistas, mas exatamente sobre a individualização, matéria preciosa do nosso tempo. Se consideramos o romance como metonímia do mundo, é possível encontrar na ficção (nas questões que só para a ficção são possíveis) de Eliane Brum os elementos constituidores de uma história cultural contemporânea por meio da qual as testemunhas ficcionais são também documento desse tempo. E se insistimos na tópica do Tempo é porque Uma duas convoca para seu texto eventos e polêmicas pertinentes ao contexto de sua produção que, no limite, aludem aos termos e extremos do humano como abuso sexual infantil, aborto, eutanásia, depressão, assexualidade, hipersexualidade, solidão, dentre outros temas delicados. Entendidos como tabus e matrizes do mal-estar na civilização, as tópicas que preenchem o romance da autora gaúcha sugerem não a fragilidade, mas a fragmentação.

Paralelamente surge no romance o conflito entre o devir animal e a essência humana por meio dos corpos e das subjetividades das personagens, confrontadas sempre pela ameaça de uma, (duas) perda(s):

Precisa chegar muito perto para enxergar os olhos abertos da mãe. Perto o suficiente para sentir o cheiro rançoso da pele. A mãe tinha sido desinfetada, mas ainda está meio podre. A humanidade do corpo da mãe resistindo aos produtos químicos e à tecnologia. Exalando a verdade de que os vivos cheiram mal, no fim cada vez pior. (BRUM, 2011, p. 31)

Assim, destaca-se precipuamente a seleção lexical utilizada para compor o ambiente semântico propício no trecho anteriormente citado: cheiro rançoso, desinfetar, podridão, produto químico, tecnologia. O corpo da mãe é algo cuja sacralidade de longe foi perdida (desde que passou a ser apenas a "carne enrodilhada") e, a esta altura do livro, nada mais é que um espaço qualquer contaminado, infectado, infeccionado, acometido a demandar um antídoto tecnológico para as enfermidades físicas. Nesse sentido, o uso do vocabulário operacionalizado pelo narrador aponta a concorrência para o que Susan Sontag (2007) 
demonstrou: socialmente (e literariamente), a doença é sempre metáfora ou punição.

Com isso, passa a ser relevante o fato de que na narrativa de Brum a falência do corpo e da subjetividade de Maria Lúcia seja determinante para potencializar o permanente estado de crise de Laura, derivado do conflito latente de identidades geminadas entre ambas, o que nos obriga a evocar o próprio título do livro e o corte gráfico existente entre as palavras "uma" e "duas" na capa de cores cítricas e ácidas. Se num primeiro momento a filha é obrigada a lidar com o estado ambivalente da mãe (meio morta, meio viva) no chão do apartamento, fato que acaba desencadeando a interdição jurídica da progenitora, o segundo momento do ápice crítico corresponde à descoberta da doença materna. A notícia de que há cânceres destruindo o corpo de Maria Lúcia reativa a memória de Laura, lembrando-a do afogamento infantil provocado pela própria mãe:

Sabe que escuta cada palavra. Não é que não escute. Ela escuta. Mas está no fundo do mar, e o som ressoa abafado entre suas orelhas. Não, não está no fundo da piscina. Não, da banheira. A mãe não a salvou da piscina quando puxou seus cabelos. A mãe a tirou da banheira da casa de esquina quando ela se afogava. Mas quem a tinha colocado lá. Mãe, quem me afogou na banheira quando eu era bebê? (BRUM, 2011, p. 125)

As engrenagens das relações estão, portanto, gastas e arruinadas porque identificam um processo de queda queé experiência de encontro com o Inferno, como já citado anteriormente.

Diante da iminente morte da personagem Maria Lúcia, a ambiência hospitalar encena os impasses tecnotópicos contemporâneos, uma vez que à narração e à Laura caberão os papéis de confrontar o discurso asséptico pseudo-humanista dos profissionais da área da saúde. Contra o perecimento e a falibilidade surgem as cirurgias permeadas de técnicas para retiradas estratégicas do que é maligno no corpo. Poder-se-ia dizer que a favor das soluções tecnotópicas previstas para a salvação simbólica da mãe está o pavor humano no confronto com a sua própria finitude:

A médica está no controle agora e pode seguir em seu discurso branco. O branco, ela pensa, não é a soma de todas as cores, mas a ausência de todos os sentimentos. O branco não tem dor nem medo nem vilania. Por isso é a cor da paz, porque é a uma soma que subtrai o humano. (BRUM, 2011, p. 126)

Cientes da falácia contida nas promessas da medicina, mãe e filha fogem do hospital numa busca por alternativas de sobrevivência. Diante do impasse, o romance de Eliane Brum chega à sua principal dilemática: Maria Lúcia pede que Laura a mate. É neste ponto que Uma duas encampa uma discussão profícua a respeito do que é a vida e, consequentemente, do que é morrer e 
matar a partir de uma perspectiva antropocêntrica que inviabiliza a prerrogativa científica/ biologizante.

Jurandir Freire Costa, em O vestígio e a aura (2005), historiciza a chegada de nosso tempo aos empreendimentos da bioidentidade, premissa operante da razão contemporânea. Mesmo aderindo ao pressuposto pacto ficcional proposto por uma das narradoras do romance de Brum, a tônica das investigações de Costa podem nos interessar pelo fato de buscarem compreender a constituição das personalidades somáticas de nosso tempo:

A noção de mundo político perdeu a sua primazia absoluta e passou a concorrer com a de mundo ecológico. A ideia da sociedade como teatro da ação humana descomprometida com as necessidades "animais" foi abalada em seus pilares. O justo é o saudável; o resto é o que se adapta ao programa da vida bem-sucedida, do ponto de vista biológico. (COSTA, 2005, p. 191)

Esta parece ser a base do dilema experimentado pela personagem Laura, obcecada pelo pedido da mãe para que execute o matricídio. Assim, a hipótese de assassinar Maria Lúcia empreende uma discussão ética para a qual o romance dedica algumas páginas: é possível evitar um sofrimento imputando a alguém outro sofrimento humano? É a morte o fim derradeiro ou a perenidade de uma doença pode ser o regozijo sádico de quem assiste um doente devir morto?

Tais ponderações aparecem na voz narrativa da filha. $\mathrm{O}$ excerto, apesar de grande, é bastante conveniente à leitura que ora construímos:

O que eu devia fazer é levá-la de volta ao hospital, como uma boa filha preocupada. E deixar que os médicos a abram. E façam tudo o que a sua onipotência gananciosa e a nossa conta bancária permita. Tudo o que de pior eu sonhei para ela e inteiramente dentro da lei. Algum tempo depois ela morrerá em dor, sozinha, numa UTI, toda remendada, careca pela quimioterapia, presa a tubos e fios, sem poder falar nem me alcançar. E pronto, eu estarei livre e perfeitamente integrada à sociedade. Essa, afinal, é a forma mais cruel de matá-la. E eu ainda serei uma filha dedicada. Para o bem da mãe, a internei no hospital para que fosse salva contra sua vontade. Lutarei ao lado dela pela sua vida até o fim, sem jamais esmorecer. Mais uma cirurgia? Claro. Surgiu um novo medicamento? Evidente que tentaremos! Tem efeitos colaterais dolorosos e ainda não totalmente conhecidos? Que lástima, mas precisamos pensar no bem maior, que é a salvação da sua vida. Aumentar as sessões de quimioterapia? Com certeza, o importante é lutar. Quem sabe não tentamos também uma radioterapia? (BRUM, 2011, p. 136)

Sobressai, na citação, a permissividade irônica da narradora que enxerga na luta (avaliada pelos médicos assépticos de branco) o único compromisso ético que pode ser assumido pelos 
que estão implicados numa doença terminal. Não obstante, o recurso permanente da ironia no romance enquadra mais uma vez os sentidos replicados, duplos, ambíguos e ambivalentes da narratividade em que as personagens parecem ter dificuldade de construir e reificar as suas negatividades enquanto metonímias do mundo. Ou seja: a enunciação irônica reforça a dificuldade dos conflitos e dilemas presentes na trama.

Estes embates (bio)éticos adquirem cada vez mais espaço nas discussões contemporâneas pelo fato de confrontarem as instâncias humanas participantes e que representam também as obrigações legais e jurídicas dos envolvidos. Desse modo, a narrativa de Eliane Brum parece não se afastar também de uma tarefa jornalística orientada pelo objetivo de trazer para o campo da informação e das discussões as problemáticas humanas instigadoras e polêmicas, conforme já apontamos anteriormente.

A eutanásia, considerada crime na maioria dos códigos penais, encontra cada vez mais espaço enquanto alternativa em Uma duas. A atitude de Laura diante da iminente morte de Maria Lúcia também não pode ser lida a partir apenas pela ótica da compaixão por parte da filha porque implica, necessariamente, a dualidade irônica do conflito ético, como já dito. Julia Kristeva, em Pouvoirs de l'horreur, analisa as relações da dor com o horror, do abjeto e do grotesco. Pressupondo que a ação horrorosa ou abjeta lida com os interditos de nossa fragilidade e mesquinhez, aponta:

L'abject est apparanté à la perversion. Le sentiment d'abjection que j'éprouve s'ancre dans le surmoi. L'abject est pervers car il n'abandonne ni assume un interdit, une règle ou une loi; mais les detourne, fourvoie, corrompt; s'en sert, en use, pour mieux les dénier. Il tue au nom de la vie: c'est le despote progressiste; il vit au service de la mort: c'est le tranfiquant généticien; il réapprivoise la souffrance de l'autre pour son proper bien: c'est le cyinique (et le psychanalyste); il rassoit son pouvoir narcissique en feignant d'exposer ses abîmes: c'est l'artiste qui exerce son art comme une "affaire"... La corruption est sa figure la plus répandue, la plus évidente. Elle est la figure socialisée de l'abject. (KRISTEVA, 1980, p. 23)

Destacamos, do excerto anterior, a preocupação de Kristeva em compreender a abjeção como prática dúbia que nem abandona nem assume um interdito, deturpando-o, o que é verificado no romance de Brum. No caso das protagonistas, a filha, ainda que assumindo narrativamente o lugar e o discurso daquela que sofreu todas as consequências de uma memória (adoentada por uma sucessão de pequenos horrores simbólicos) tecida a quatro mãos, também regozija a possibilidade de sua cisão humana diante da monstruosa criatura que se tornou elas duas indivisíveis e indistintas: "Será que a morte da mãe é a vida da filha? Naquele tempo eu já sabia que não havia espaço para nós duas na mesma vida, no mesmo corpo. Uma de nós precisava morrer. E eu queria viver." (BRUM, 2011, p. 134). 
A construção dramática da morte de Maria Lúcia, preparada calculadamente pela filha, é igualmente operada pelo signo do cinismo e da ironia, considerando que Laura, convencida pela mãe e por si mesma a encerrar o sofrimento de ambas, provoca a morte da mãe durante uma sessão de $A$ Noviça Rebelde. O capítulo inteiro da morte intertextualiza a canção "The Sound of Music". Como no filme, um rito de passagem:

Há duas vozes dentro de mim. Tenho de me partir para suportar. Levanto num repente. Mas é apenas ilusão. Só minhas pernas se moveram batendo na cama e fazendo um barulho de metal. Desculpa, mãe. Ela não responde. Me viro para enxergar seu rosto e encontro uma expressão infantil. Minha mãe está extasiada com o filme. O que aconteceu com ela? Ela sempre detestou esse filme, até porque eu adorava. Ora, o que está acontecendo, sua estúpida. Ela está morrendo. A morte muda a perspectiva das coisas. Ou pelo menos eu acho que muda. Não consigo tirar os olhos do rosto dela. Ela parece não perceber a minha presença. Ela nem está ali. Minha mãe pisa o tapete verde das montanhas dos arredores de Salzburgo. Ou finge pisar. Finge tanto que acredita. (BRUM, 2011, p. 167)

Se por um lado a linguagem cínica encabeça a narratividade, há que se pontuar que em menores situações a narração permite uma voz lírica. Este tipo de enunciação, no entanto, é frontal e rapidamente combatida pela análise pós-humana da narração: "Como alguém mata a sua mãe? Não é uma pergunta moral para mim. É técnica." (BRUM, 2011, p. 159).

\section{Metaescrita do corpo ou "A quem interessa o meu corpo de letras?"}

O corpo tornou-se o espaço da criação e da utopia.

Francisco Ortega. O corpo incerto

Apesar de o romance Uma duas brutalizar e até em certa altura encarnar um discurso cinicamente violento que desaloja o humano da(s) sua(s) medida(s), seria incorreto dizer que se trata de um livro anti-humanista. Isto porque para ambas as personagens principais, verifica-se uma cultura tanto de escrita quanto de leitura, valorizadas sobretudo pelas suas funcionalidades didático-pedagógicas. Como se as personagens buscassem, por meio da ação de escrever (especialmente), a constituição de um fulgor ou de uma aura capaz de ressignificar a existência e as experiências.

A narrativa, aliás, começa por meio da escrita de Laura que compreende sua possibilidade de existência e respiração por meio do livro que principia a escrever: "Começo a escrever este livro enquanto minha mãe tenta arrombar a porta com suas unhas de velha. Porque é realidade demais para a realidade. Eu preciso de uma chance. Eu quero uma chance. Ela também." (BRUM, 2011, p. 01). A afirmativa do excesso de realidade cria no interior do livro 
uma disputa curiosa que parece querer desafiar o leitor num outro conflito: o real e a ficção. Todas as três narrações evidenciam uma conexão de temática cruel que pareceria impensável no campo das factualidades, o que explicaria o compromisso dos três capítulos iniciais em balizar os esquemas desta escrita, necessariamente subordinada a alguns pressupostos da narradora: escrever interrompe o sangue aberto; não há espaço para metáforas. Advoga a filha narradora: "Eu não sei fazer metáforas porque não compreendo metáforas. Para mim tudo é literal." (BRUM, 2011, p. 15).

A crueza do texto prevê a sua própria organicidade ao insistir nas imagens sanguíneas (há um excesso de cortes e sangue excessivo no livro) como resultado de um corpo em agonia e permanente estado de erupção e iminente fratura. Se o útero é para sempre, como afirma Laura, a escrita parece ser o espaço de um nascimento à fórceps mediado por muitos líquidos orgânicos. Esta busca por espaço, identidade e respiração parece ser a única possibilidade diante do mundo distópico estabelecido com a mãe e sua autoridade sobre o "corpo torturado que nem é posse, mas extensão" (BRUM, 2011, p. 16). É possível, com isso, verificar aquilo Francisco Ortega em O Corpo Incerto - Corporeidades, Tecnologias Médicas e Cultura Contemporânea (2012) entende como busca pela personalização do corpo por meio da externalização da subjetividade: o corpo de Laura enquanto construção, devir corpo-escrita, uma vez que os cortes que ela em si retalha compõem o tecido doloroso de sua paisagem orgânica que informa: "Como meus braços bordados pelas cicatrizes de todas as tentativas de me separar do corpo de minha mãe. (...) Este ritual que agora pinga de mim como um fracasso. Eu corto corto corto e ainda não sei que existo. Continuo sem corpo." (BRUM, 2011, p. 15).

Evocando Benjamin, poderíamos avaliar a narrativa de Laura como uma história atravessada pela barbárie. Ao insistir na produção de um documento (o livro em devir) cuja matéria atesta a sua infância arruinada e o consequente legado que o seu corpo, também monumento de cultura representa, a narradora-personagem reivindica uma voz singular que possa, efetivamente, cindir com o duplo enraizado na geminação uterina (lembremos, novamente, da imagem provocada pela assertiva do início do romance: "o útero é para sempre"). Esta aposta de resistência pode ser perfeitamente compreendida a partir do que aponta Jeanne Marie Gagnebin em Lembrar escrever esquecer (2009) sobre o fim da narrativa tradicional, sugerindo que a narração resistente no século XX alude sempre ao "gênero tristemente recorrente" (p. 49) em que a memória traumática tenta (se) recompor e (se) reelaborar para, afinal, resistir.

Pertencem à Laura a narração do primeiro e do último capítulo da obra, muito embora haja outras disputas pela voz da narração. A mãe eventualmente reivindica seu território narrativo, procurando desalojar a prevalência da filha no discurso: 
Ainda bem que você saiu. Eu já estava me sufocando com sua presença no ar que eu quase não respiro. Não se iluda, eu também sinto seus olhos e suas unhas ainda jovens arranhando a minha porta. Você, minha filha, me dá poderes sobrenaturais apenas porque tem medo da sua força. (...) É para seus leitores que escrevo. Mas a decisão de publicar também a minha versão é sua. Será sempre sua. Eu não deixarei que você coloque mais uma violência na minha conta. (BRUM, 2011, p. 71)

A polifonia adquire, portanto, um efeito pretensioso de justiça, uma vez que pressupõe um pacto pela "realidade" e pelo oferecimento das versões outras de uma história que poderia ser apenas de Laura. Por outro lado, a filha, na sua condição subalterna no cenário patriarcal, bem como submissa ao poderio materno, persiste na tarefa do corpo que tece e também procura desde os capítulos iniciais cercar o seu texto da disputa das outras vozes:

Minha mãe sabe. Acordei com sua voz dentro da minha cabeça. Não é assim. Você está contando tudo errado. Eu quero dar a minha versão. Eu tenho direito à minha voz nesta história. Meu coração disparou e por um não tempo fiquei paralisada de medo enquanto sua voz tentava empurrar a minha para a escuridão. Prometi deixá-la falar. E meus batimentos voltaram ao normal.

Mas menti. Sou eu que falo. Desta vez, é a minha voz. As palavras são todas minhas. Minhas. A narradora agora sou eu. E, para ela, a história chegou ao fim. (BRUM, 2011, p. 38)

É notável verificar o esforço da narração de Laura, sempre orientada pela tentativa de construção a partir dos entulhos das ruínas circulares da subjetividade. Nesse sentido, a aproximação do fim e da morte da mãe seria também garantia da prevalência da sua própria voz e da emergência de uma identidade menos adoecida.

As atividades predominantemente humanistas, isto é, leitura e escrita, certificadas pela assertividade do último excerto reproduzido nos levam à problematização de uma outra questão que se desdobra no romance de Brum. Se, conforme afirma Edward W. Said em Humanismo e crítica democrática (2007), "o leitor é uma característica central de todo o Humanismo" (p.65), é necessário avaliar a personagem que surge no décimo sexto capítulo de Uma duas. Surgido numa livraria, o homem um pouco calvo e com óculos de aros grossos tem "o segundo livro do Harry Potter no colo" (BRUM, 2011, p. 76).

A livraria, desdobramento da cultura massiva e capitalista das bibliotecas infinitas que Borges sonhava, é palco para o encontro de Laura com o personagem masculino com quem ela passa a se encontrar todas as semanas. Possivelmente inspirada pelo mesmo Borges, Eliane Brum afere ao espaço dos livros uma hipótese de reabilitação para Laura, na medida em que os encontros vão se caracterizando como rituais de uma passagem em que 
o livro de Harry Potter funcionaria como índice do descolamento simbólico da mãe para livrar-se de uma subjetividade infanto-juvenil que domina a filha:

Ela me roubou as palavras, a minha mãe. Sinto sua presença em tudo, na minha pele, no cheiro do meu corpo, no corpo das letras que escrevi. E o indizível agora se tornou não mais uma busca pelo que está fora das palavras, mas uma impotência. (BRUM, 2011, p. 89)

O personagem, não gratuitamente um massagista que gosta de tocar as pessoas, parece querer reabilitar Laura na confecção de si mesma: "Acho que você deveria apenas escrever. Talvez o novo nem exista. Talvez seja isso, um livro para mostrar que não existe nada novo. (...) E não faz mal. Estamos aqui e é o suficiente. Você escreve e é o suficiente." (BRUM, 2011, p. 105), diz para a protagonista. Massoterapeuta, como profissional que toca as massas, o homem é o único personagem que verdadeiramente vai ao encontro de Laura. Maior ironia, impensável.

Nos capítulos seguintes verifica-se que o personagem continua compondo espaços simbólicos nos dilemas cada vez mais radicais de Laura. E o que Brum parece querer nos sugerir é que "o homem com o livro do Harry Potter" também tem, junto com a escrita, a função de re-humanizar a protagonista. Tal empreendimento, apesar de custoso, passa a ocorrer durante os encontros na livraria até que culminam na ida ao consultório de massagem do personagem masculino, onde toca "a teia intrincada de pequenas cicatrizes do corpo sem que ele nada pergunte. Como um mapa do metrô, eu penso, as minhas cicatrizes. Mas não. Ele dedilha minhas marcas e quase posso ouvir música." (BRUM, 2011, p. 157).

O processo de re-humanização, no entanto, é interrompido pela própria Laura após uma crise provocada pela sensibilização oriunda do toque e da projeção de uma intimidade experienciada com o personagem masculino. A crise deflagra a radicalidade de seu conflito sintomático amplamente pontuado na primeira parte deste ensaio: matar ou não a mãe. Ou matar a parte mais doentia de si.

Sendo ou não metafórica a discussão sugerida por Eliane Brum em seu primeiro romance, fato é que a morte da mãe enseja uma discussão atualíssima sobre as condições de nossa cultura pós-humanista. Enquanto literalmente a morte de Maria Lúcia pode ser pensada a partir da necessidade de extermínio de uma figura familiar de poder, revelando os conflitos totêmicos que disto derivam, por outro lado, a necessidade de matar tal figura negativamente poderosa também sugere uma procura sobre os limites das identidades e subjetividades próprias. Demandar matar, no quadro pós-humanista, não revelaria apenas uma desqualificação do humano, mas aquilo já apontado por Agamben sobre uma política precípua de dessacralização do corpo. 
Uma duas revela, com efeito, o corpo humano, organicizando-o para além do seu lugar fisiológico, fazendo dele suporte, grau de escrita, pós-tatuagem (Laura desenha e escreve no próprio corpo). A tática exógena, voltada para a execução estética de uma obra (Laura precisa escrever um livro) atende a uma busca pela cura (Mas, lembrando a matriz borgeana sobre a Biblioteca, sabe-se que o número daqueles contemplados pela possibilidade de Reabilitação é próximo de zero). Consequentemente, pode-se entender o lugar da escrita na narrativa de Eliane Brum por meio de uma procura pela desterritorialização já que surge enquanto libelo contra o um sistema familiar autocrático. Seria este um corpo sem órgãos, conforme o entendeu Deleuze? Faltaria a potência, mas a procura pela metamorfose, isto é, pela possibilidade de transformar este corpo em algo para além da sua propriedade fisiologicamente funcional já indicaria uma semelhança.

A consequente tarefa do livro parece ser a ressignificação do corpo por meio das mãos por onde a obra se reifica. No último capítulo, finalmente, a narração demonstra que esta ressignificação atende a uma carência de aura, por meio da qual, lembrando Benjamin, poderíamos encontrar os sentidos da experiência. Uma duas sugere, com isso, que a escrita de um livro, ainda que sob o peso de uma legião infernal, reelabora um pacto do humano com seus demônios. Nesta história, no entanto, dar sentido aos monstros e males significa persistir e resistir contra o excesso de realidade.

\begin{abstract}
Eliane Brum's first novel Uma duas raises a number of considerations about traditions and (post) humanist discourses. The narrative is built from the conflict of subjectivities (of a daughter and her mother) and seeks to understand how an unhealthy human legacy of relationships confronts individuals and their permanent state of precariousness and ruin through an aggressive memory. The first part of this article proposes to read the narrative and its connections with the posthumanist senses derived from it, seeking to understand brutalization as a loss both of the aura of individuals and of their works. The second part of the text discusses how writing relocates the character Laura in her humanity, relieving her of the reason for her dystopian hybrid identity semi-attached to the "large and hard breast" of Maria Lucia, her mother.
\end{abstract}

Keywords: Brazilian Literature, Eliane Brum, poetics of ruin. 


\section{REFERÊNCIAS}

AGAMBEN, Giorgio. A linguagem e a morte. Belo Horizonte: EdUFMG, 2006.

. Homo sacer - O poder soberano e a vida nua. Belo Horizonte:

Editora UFMG, 2007.

BENJAMIN, Walter. Magia e técnica, arte e política. São Paulo: Brasiliense, 1985.

BRUM, Eliane. Uma duas. São Paulo: Leya, 2011.

COSTA, Jurandir Freire. O vestígio e a aura. Rio de Janeiro: Garamond, 2005.

GAGNEBIM, Jeanne Marie. Lembrar escrever esquecer. São Paulo: Editora 34, 2009.

KRISTEVA, Julia. Pouvoirs de l'horreur. Paris: Seuil, 1983.

ORTEGA, Francisco. O corpo incerto - corporeidade, tecnologias médicas e cultura contemporânea. Rio de Janeiro: Garamond, 2012.

SAID, Edward W. Humanismo e crítica democrática. São Paulo: Companhia das Letras, 2007.

SLOTERDIJK, Peter. Regras para o parque humano - uma resposta à carta de Heidegger sobre o humanismo. São Paulo: Estação Liberdade, 2000.

SONTAG, Susan. A doença como metáfora. São Paulo: Companhia das Letras, 2007. 